\title{
Gobernabilidad en las zonas metropolitanas mexicanas. El caso de Puerto Vallarta
}

\section{Governability in the Mexican metropolitan areas. The Puerto Vallarta case}

\author{
doi: http://dx.doi.org/10.32870/ \\ espiral.v25i73.7003
}

\section{Resumen}

El presente artículo tiene como objetivo analizar si existe gobernabilidad en la zona metropolitana de Puerto Vallarta, México. Para ello, se revisan los alcances que ha tenido el convenio de coordinación pactado hace ocho años por los tres órdenes de Gobierno para dicha metrópoli. El trabajo realizado abona a los estudios de la gobernabilidad metropolitana en el país, a partir de un caso de estudio que se caracteriza por tener un dinamismo económico, demográfico y urbano. Los resultados que arroja esta investigación exploratoria es que los obstáculos para llevar a cabo una efectiva gestión metropolitana en la zona analizada han sido fuertes, a pesar de que en ello han participado varios actores importantes. Los resultados permiten adelantar que continuarán las demandas de los ciudadanos de la zona metropolitana analizada, quienes exigen una mayor calidad de vida.

Palabras clave: gobernabilidad, coordinación metropolitana, zona metropolitana,

Puerto Vallarta, México.

\author{
Érika Patricia Cárdenas
}

\begin{abstract}
This article analyzes if governability exists in the metropolitan area of Puerto Vallarta, Mexico. For that, we analyze the scope of the coordination contract agreed eight years ago by the three government orders. The pertinence of this work is that it contributes to the studies of the metropolitan governability in the country, starting from a case study which is characterized by an economic, demographic and urban dynamism. The results of this exploratory research are that the obstacles to effective metropolitan management have been stronger, despite the participation of several important actors. Thus, it is predicted that the demands of citizens for a higher quality of life will continue.
\end{abstract}

Keywords: Governability, metropolitan coordination, metropolitan area, Puerto Vallarta, Mexico.

-Profesora-Investigadora de El Colegio de Jalisco, México. ORCID: http://orcid.org/0000-00032293-2784_erika.cardenas@coljal.edu.mx

Fecha de recepción: 15 de septiembre de 2017. Fecha de aceptación: 26 de abril de 2018. 


\section{Introducción}

México, en el siglo XXI, se consolidó como un país urbano, pues la mayoría de su población se concentra en ciudades. En el 2010, se estimó que 63.8 millones de mexicanos vivían en un área urbana, lo que representa el $56.8 \%$ de la población nacional (Secretaría de Desarrollo Social, Consejo Nacional de Población, e Instituto Nacional de Estadística y Geografía, 2013). En pocas décadas, el país ha registrado un alto crecimiento demográfico y urbano, por lo que los límites político-administrativos que originalmente tenían las ciudades han sido rebasados. Por lo anterior, las instituciones gubernamentales han enfatizado que el país es metropolitano, aunque también se debe reconocer que en México todavía existen muchas comunidades rurales, pequeñas poblaciones y ciudades que aún no forman metrópolis.

En este marco, varios de los problemas de México también son de carácter metropolitano, tales como la pobreza patrimonial y alimentaria que padecen los habitantes de las ciudades, los inconvenientes medioambientales, la falta de movilidad urbana sustentable y la inseguridad pública, entre otros (Programa de las Naciones Unidas para los Asentamientos Humanos y Secretaría de Desarrollo Social, 2011). No obstante, la problemática se complica aún más en el país porque no existe "una instancia de gobierno o la noción de una estructura de gobernabilidad que se adecue a las necesidades de la población que vive en estas áreas metropolitanas" (Ward, 2011, p. 240). Esta situación se agrava en las zonas metropolitanas que registran un alto crecimiento demográfico y urbano, como son las fronterizas y las turísticas, así como en las zonas metropolitanas de carácter interestatal, donde se involucra la participación de un mayor número de actores políticos.

Además, se debe mencionar que en la constitución mexicana no se define el término zona metropolitana (Ward, 
2011 , p. 220). Solamente dos artículos de la constitución mexicana tratan al fenómeno metropolitano: el 115, fracción VI, y el 122 (Ward, 2011, pp. 220-221). ${ }^{1}$ El primer artículo mencionado señala textualmente:

Cuando dos o más centros urbanos situados en territorios municipales de dos o más entidades federativas formen o tiendan a formar una continuidad demográfica, la federación, las entidades federativas y los municipios respectivos, en el ámbito de sus competencias, planearán y regularán de manera conjunta y coordinada el desarrollo de dichos centros con apego a la ley federal de la materia (Constitución Política de los Estados Unidos Mexicanos, 20I4, p. 206).

De la cita anterior, llama la atención que el marco jurídico no contempla las estructuras ni los recursos para llevar a cabo una efectiva coordinación metropolitana (Ward, 2011, p. 222), aspectos sumamente importantes para darle obligatoriedad y estimularla. Cabe señalar que en 1976 la Ley General de Asentamientos Humanos dio origen a los primeros instrumentos de regulación del fenómeno de conurbación: las declaratorias de conurbación y los programas de desarrollo urbano de zonas conurbadas (Zentella, 2005, p. 232).

Ahora bien, en el 2004 se dio un paso significativo cuando la Secretaría de Desarrollo Social (SEDESOL), el Consejo Nacional de Población (CONAPO) y el Instituto Nacional de Estadística y Geográfica (INEGI) se dieron a la tarea de definir lo que era una zona metropolitana, ${ }^{2}$ además de establecer una metodología para delimitar las zonas metropolitanas

I. Cabe señalar que en la Cámara de Diputados Federal, en el periodo que va de 2000 al 2012 , se presentaron un total de doce iniciativas que versaron sobre el fenómeno metropolitano (Arellano, 20I3b, p. 24).

2. SEDESOL, CONAPO e INEGI definen como una zona metropolitana al "conjunto de dos o más municipios donde se localiza una ciudad con más de 50000 habitantes, cuya área urbana, funciones y actividades rebasan el límite que originalmente lo contenía, incorporando como parte de sí misma o su área de influencia directa 
en el país. Del primer ejercicio, se identificó que en el país había cincuenta y cinco zonas metropolitanas (Secretaría de Desarrollo Social, Consejo Nacional de Población, e Instituto Nacional de Estadística y Geografía, 2004). Con el paso del tiempo, dicho ejercicio se ha actualizado, y para el 2012 se delimitaron cincuenta y nueve zonas metropolitanas (Secretaría de Desarrollo Social, Consejo Nacional de Población, e Instituto Nacional de Estadística y Geografía, 2012).

A partir de la delimitación hecha por dichos organismos, ha habido un auge del número de trabajos que analizan a las zonas metropolitanas desde distintas perspectivas, tales como: 1) urbano-territorial, 2) demográfica, 3) social, 4) económica, 5) político-institucional y 6) la combinación de varias dimensiones (Cárdenas, 2014, p. 73).

Otro hecho memorable en la constitución y organización de las zonas metropolitanas del país fue la promulgación de la nueva Ley General de Asentamientos Humanos, Ordenamiento Territorial y Desarrollo Urbano, el 28 de noviembre de 2016, pues esta no solamente incluye definiciones interesantes a conceptos como desarrollo metropolitano, zonas metropolitanas y megalópolis, entre muchos más, sino que destina artículos precisos para la delimitación, organización y funcionamiento de dichos centros urbanos, como se puede observar en los artículos que van del 31 al 35. Asimismo, la citada ley trata de ir un paso más allá al abordar el tema de la gobernanza metropolitana, como quedó establecido en los artículos que van del 36 al 39 (Cámara de Diputados, 2016). Hubiera sido interesante que en dicho ejercicio también se contemplaran los incentivos para impulsar la coordinación metropolitana, así como las sanciones por su obstaculización. 
Algunos autores como Iracheta (2010, 2012), Iracheta e Iracheta (2014) Salinas (2017) y Zentella (2005), entre otros, han dado cuenta de los graves problemas que enfrentan las zonas metropolitanas del país y de que los mecanismos para superarlos son frágiles. Uno de dichos mecanismos es la coordinación metropolitana, que se "puede lograr de tres maneras diferentes: mediante acuerdos bilaterales entre municipalidades, mediante la descentralización regional de agencias públicas, o mediante un Gobierno regional en el cual el gobernador ejerce su influencia" (Ward, 2011, p. 234). En este marco, se observa que en principio en México no existe la estructura para que se dé gobernabilidad metropolitana, entendida como el estado de un territorio en el que es posible ejecutar políticas públicas y acciones colectivas capaces de resolver problemas y desarrollar el territorio en cuestión (Lefévre, 2005, p. 195).

Otra definición señala que "la gobernabilidad es una propiedad específica de los Gobiernos y de los actores sociopolíticos" (Camou, 1995, citado por Ramírez, 1999, p. 191). Asimismo, se agrega que la gobernabilidad es una "interfase y mediación entre el Estado en sus diversas expresiones y los actores sociales, sean estos vistos desde la óptica de la ciudadanía o desde la perspectiva de las asociaciones de la sociedad civil" (Olvera, 1999, citado por Ramírez, 1999, p. 192). Dicho planteamiento es interesante por dos razones: 1) se reconoce el proceso de transición democrática que empezaron vivir varias ciudades mexicanas en la década de los noventa del siglo pasado, y lo que ello implicó; y 2) se asume que la gobernabilidad no es un asunto que solamente atañe al Gobierno. De igual manera, se reconoce que "la gobernabilidad y la ciudadanía política en las áreas metropolitanas se encuentra en su fase instituyente" (Ramírez, 1999, p. 191).

Juan Carlos Zentella es otro de los autores que retoma el término de gobernabilidad urbana para enfatizar que 
han desaparecido los esquemas clásicos de centro-periferia, pues hoy día existe una pluralidad de actores (Zentella, 2005, p. 236).

Por su parte, Lefévre expone que uno de los pilares fundamentales en la construcción de la gobernabilidad metropolitana es el de la legitimidad. Esta puede ser política, funcional o social. Para que se dé la legitimidad política, dicho autor señala que: 1) los Gobiernos y los arreglos metropolitanos deben ser aceptados por otras unidades gubernamentales locales, 2) se debe tratar la dominación de las ciudades centrales, 3) se debe equilibrar el poder metropolitano con la participación vecinal, y 4) se deben democratizar los ordenamientos metropolitanos (Lefévre, 2005, pp. 223-229). Asimismo, el autor establece una serie de recomendaciones para incentivar la legitimidad funcional y social (pp. 230-238). De igual manera, estudiosos del fenómeno comentan que "la legitimidad y la eficacia son las dos características básicas de la gobernabilidad" (Arbos y Giner, 1993, citado por Ramírez, 1999, p. 190).

Es importante recalcar que en los últimos años el término gobernanza ha cobrado nuevos bríos y nuevos adeptos, pero ¿qué significa dicho concepto? En primer lugar, Cerrillo (2005) menciona que la "gobernanza se asocia a una mayor implicación de actores no gubernamentales en el diseño e implementación de las políticas públicas y al fin [y] al cabo en la definición del interés general" (p. 9), mientras que Peters y Pierre comentan que la idea de gobernanza es como "una nueva manera de pensar sobre las capacidades estatales y las relaciones entre el Estado y la sociedad" (2005, p. 37), esto debido a los cambios que se han venido suscitando en las últimas décadas.

Por su parte, Mayntz refiere que "la gobernanza se utiliza ahora con frecuencia para indicar una nueva manera de gobernar que es diferente del modelo de control jerárquico, un modelo más cooperativo en el que los actores estatales 
y los no estatales participan en redes mixtas públicosprivadas" (2005, p. 83), y al mismo tiempo comenta sobre la generalización del uso del vocablo gobernanza en más sectores.

Rhodes (2005) concuerda con el primer punto señalado por Mayntz, pues enfatiza que la gobernanza implica un cambio en el significado de gobierno, refiriéndose a un nuevo proceso de gobierno o un cambio en la condición de la norma establecida o al nuevo método con el que se gobierna la sociedad (pp. 99-100).

Prats, por su parte, señala que en algunas ocasiones el concepto de gobernanza se emplea como sinónimo de gobernabilidad, cuando tienen significados diferentes. El primero "es básicamente una herramienta analítica y descriptiva. Pero en la medida en que una pauta de governance puede verse como el resultado de las intervenciones de los actores, también tiene una dimensión normativa" (Prats, 2005, p. 166). El segundo, gobernabilidad, se refiere a la "cualidad conjunta de un sistema sociopolítico para gobernarse a sí mismo en el contexto de otros sistemas más amplios de los que forma parte. Esta cualidad depende del ajuste efectivo y legitimo entre las necesidades y las capacidades de gobernación" (Kooiman, 2003, citado por Prats, 2005, p. 168).

Ahora bien, Lefévre identificó que "los modelos de gobernabilidad se pueden dividir en dos categorías: aquellos que operan a través de construcción institucional, y los que los hacen por medio de la cooperación" (2005, p. 200). ${ }^{3}$ Como ya se indicó, en México los tres órdenes de Gobierno permiten la segunda opción, es decir, que entre las partes se establecen

3. Ejemplos de Gobiernos metropolitanos con estructuras fuertes: Greater London Council, la actual Comunidad Autónoma de Madrid, el Distrito Metropolitano de Quito, el Verband Region Stuttgart, The Greater London Authority y el Distrito Metropolitano de Portland. En el segundo modelo, de cooperación, se ubican como ejemplos las communautes d'agglomération y las communautes urbaines, entre otras (Lefévre, 2005, pp. 202 y 209). Cada uno de los casos presentados tiene tanto sus fortalezas como debilidades. 
acuerdos, convenios o comisiones para resolver los problemas comunes que las aquejan (Salinas, 2017, p. 154).

Cabe señalar que la zona metropolitana de Guadalajara ha sido pionera en dicho rubro, pues desde 1989 se estableció el Consejo Metropolitano de Guadalajara, "el cual tiene como atribución revisar y, en su caso, presentar propuestas para la actuación del Plan de Ordenamiento de la Zona Conurbada de Guadalajara, así como los planes parciales de desarrollo urbano de los municipios" (Arellano, 2013a, p. 85). A pesar de ello, dicha zona urbana no queda exenta de seguir presentando problemáticas que impiden lograr una efectiva coordinación metropolitana (Ward, 2011, p. 233), ${ }^{4}$ aunque en el caso de Guadalajara se debe destacar la actual instalación de instancias de coordinación metropolitana como lo son la Junta de Coordinación Metropolitana, el Instituto Metropolitano de Planeación y el Consejo Ciudadano Metropolitano, con base en la Ley de Coordinación Metropolitana del Estado de Jalisco y el Código Urbano para el Estado de Jalisco (Arias y Arellano, 2013, p. 41).

Ahora bien, por su parte, los actores públicos tanto de Puerto Vallarta como de Bahía de Banderas también siguieron la vía de la cooperación. Así pues, este texto da cuenta de cómo ha sido el proceso de coordinación en este segundo caso, y se mencionan cuáles han sido los logros que ha alcanzado y cuáles son los retos que enfrenta.

La presente investigación se realizó bajo la perspectiva metodológica cualitativa y corresponde a un estudio exploratorio. Se aplicó la técnica de análisis de revisión documental, que contiene bibliografía de referentes nacionales e internacionales sobre los conceptos de coordinación metropolitana y gobernabilidad. Asimismo, se hizo un seguimiento heme-

4. Otra de las zonas metropolitanas que ha sido ampliamente analizada es la del Valle de México. En los estudios, ha quedado asentado lo complicado que es llegar acuerdos y cumplirlos por la gran cantidad de actores involucrados en ellos (Ward, 2005; Iracheta, 2003; Salinas, 20I7). 
rográfico respecto al tema de coordinación metropolitana en los principales medios de comunicación electrónicos de Puerto Vallarta y Bahía de Banderas, en el periodo de 2010 al 2016. Asimismo, se solicitó información vía Infomex con el objetivo de contrastarla.

\section{Contextualización de la zona metropolitana de Puerto Vallarta}

\section{I.I Aspectos físico-geográficos}

La zona metropolitana de Puerto Vallarta cuenta con una superficie de $1467.3 \mathrm{~km}^{2}$. Pertenece a la región fisiográfica de la provincia de la Sierra Madre del Sur, y se caracteriza porque los suelos están formados por dos tipos de material ígneo: granito y roca volcánica (César y Arnaiz, 2001, pp. 22 y 23$)$.

Es importante señalar que el crecimiento urbano que se da en esta zona se adapta a dichos aspectos físico-geográficos, y es por ello que la zona

expone una morfología de dispersión por los grandes huecos, divisiones formadas por elementos naturales como esteros, ríos y diversos cuerpos de agua, por grandes terrenos subutilizados y por el equipamiento existente como son las instalaciones de la terminal aérea que se ubica en la parte media de la zona conurbana (Fideicomiso para el Desarrollo de la Región Centro Occidente, 2009, p. 325).

La población de la zona se ubica sobre todo en la planicie. Llama la atención el caso del municipio de Bahía de Banderas, donde la mayoría de sus principales localidades se ubica en el área plana y de alta productividad agrícola (Baños, Muñoz, y Tovar, s/f; Navarro y Gómez, 2009, p. 239).

La zona metropolitana de Puerto Vallarta cuenta con las siguientes características que la constituyen como tal: 1) está compuesta por dos municipios, Puerto Vallarta, Jalisco, 
y Bahía de Banderas, Nayarit; 2) es interestatal; 3) cuenta con un alto crecimiento poblacional; 4) tiene una vocación turística, es decir, la mayoría de la población se dedica a actividades relacionadas con el turismo; 5) su constitución correspondió a la ciudad central de Puerto Vallarta; 6) existe integración física y funcional entre las localidades de ambos municipios; y 7) se da una un flujo constante de personas, bienes y servicios (Baños, Muñoz, y Tovar, s/f).

En el mapa de la Figura 1, se puede apreciar la ubicación de la zona metropolitana de Puerto Vallarta.

Figura 1. Ubicación de la zona metropolitana de Puerto Vallarta

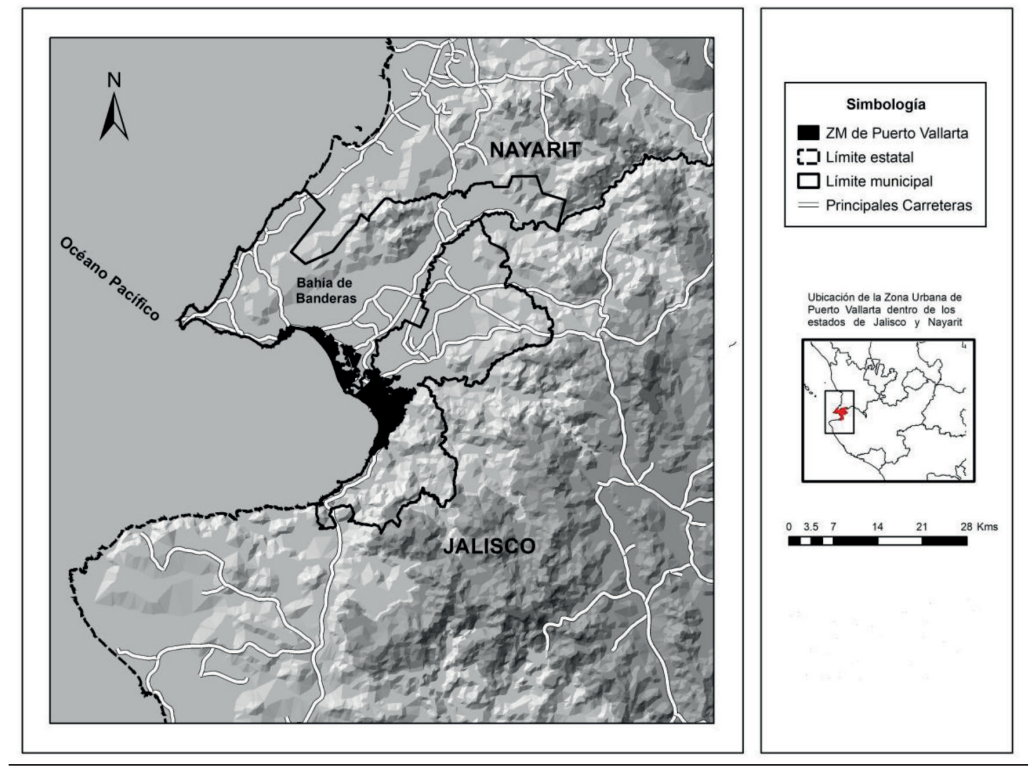

Fuente: elaborado por Jorge Federico Eufracio Jaramillo con base en Instituto Nacional de Estadística y Geografía (2014a).

Respecto a la actividad económica de la zona metropolitana de Puerto Vallarta, se destaca que en el año 2013: 1) la población económicamente activa (PEA) fue de 81304 personas; 2) la mayoría de la PEA se ubicaba en Puerto Vallarta, con el 
$76.7 \%$, a la que le seguían las localidades de Bucerías (5\%), Mezcales (4.8\%), Ixtapa (2.3\%), San José del Valle (2.2\%) y Las Juntas (1.9\%); 3) llama la atención que la mayoría de la PEA se dedicaba al sector terciario, pues el 57.5\% de dicho universo se dedicaba a servicios y el $33.4 \%$ al comercio; 4) dicho conglomerado urbano contaba con 16571 unidades económicas, el 47.2\% de las cuales se encontraba relacionado con los servicios y el $45.1 \%$ con el comercio; 5) el valor total de la producción fue de MXN 19913 846.00, de los cuales el sector servicios aportó MXN 10491365.00 y el comercio MXN 6803319.00 (Instituto Nacional de Estadística y Geografía, 2014b, pp. 108 y 109).

En cuanto a la función político-administrativa, de Puerto Vallarta y Bahía de Banderas, en términos generales, se puede señalar lo siguiente: 1) llama la atención la llegada temprana del Partido Acción Nacional (PAN) a gobernar el municipio (1995), no así para el caso de Bahía de Banderas, que tuvo alternancia política hasta el año 2011, después de sólo haber tenido gobiernos priistas, además, este último ya ha sido gobernado por una mujer, lo que no ha sucedido en Puerto Vallarta; 2) existe disparidad en los calendarios político-administrativos entre Puerto Vallarta y Bahía de Banderas; y 3) se destaca el endeudamiento que han dejado los presidentes municipales (Plascencia, 2012). Sin lugar a duda, hace falta hacer un estudio más detallado sobre el desempeño político-administrativo de cada uno de los presidentes municipales de Puerto Vallarta y Bahía de Banderas, lo que no se ahonda aquí por cuestiones de espacio. 
Tabla 1. Filiación partidista de los presidentes municipales de Puerto Vallarta, Jalisco (2007-2018)

\begin{tabular}{lll} 
Periodo & Partido & Nombre del presidente municipal \\
$2007-2009$ & PRI* $^{*}$ & Francisco Javier Bravo Carbajal \\
$2010-2012$ & PRI-PAN & Salvador González Reséndiz \\
$2012-2015$ & $\begin{array}{l}\text { Movimiento } \\
\text { Ciudadano-PT** }\end{array}$ & Ramón Demetrio Guerrero \\
& Martínez \\
$2015-2018$ & Movimiento Ciudadano & Arturo Dávalos Peña \\
\hline
\end{tabular}

*Partido Revolucionario Institucional.

** Partido del Trabajo.

Fuente: H. Ayuntamiento de Puerto Vallarta (s/f).

Tabla 2. Filiación partidista de los presidentes municipales de Bahía de Banderas, Nayarit (2008-2018)

\begin{tabular}{lll} 
Periodo & Partido & Nombre del presidente municipal \\
2008-2011 & PRI & Héctor M. Paniagua Salazar \\
$2011-2014$ & PAN & Rafael Cervantes Padilla \\
2014-2016 & PRI & José Gómez Pérez \\
2017-Actual & Coalición PAN- & Jaime Alonso Cuevas Tello \\
& PRD*-PT y PRS $*^{* *}$ & \\
\hline
\end{tabular}

*Partido de la Revolución Democrática.

** Partido de la Revolución Socialista.

Fuente: Barrón (s/f).

\section{I.2 Conformación de la zona metropolitana de Puerto Vallarta}

Por el papel central de Puerto Vallarta en el desempeño de las actividades turísticas de sol y playa a lo largo de cinco décadas, el municipio ha conformado junto con su joven vecino Bahía de Banderas una zona metropolitana de carácter interestatal. Así fue determinado por SEDESOL, CONAPO e INEGI en el 2004, aunque cabe advertir que dicho proceso tiene algo de historia, la cual se remonta a finales de la década de los setenta, cuando el Gobierno federal 
vislumbró a esta zona como una unidad física, económica y social (López Portillo, 1978). Asimismo, dicho nivel de Gobierno puso en práctica varias acciones que coadyuvaron al despegue económico de la zona, como la implantación del Fideicomiso de Bahía de Banderas, así como la instauración de la Comisión de Conurbación de la Desembocadura del Río Ameca (Jiménez, 1993). ${ }^{5}$

Ahora bien, se debe enfatizar que fue en la década de los noventa cuando se hicieron más visibles los eslabones que se tendieron hacía la conurbación en la zona metropolitana de Puerto Vallarta, porque en dicha época: 1) Bahía de Banderas se instituyó jurídicamente como municipio luego de la escisión territorial que se le hizo a Compostela; 2) Nuevo Vallarta alcanzó un ímpetu económico con la construcción de varios hoteles, condominios y resorts; y 3) la empresa Dine empezó a construir en Punta Mita, para lo cual desalojó a la comunidad local (César, 2007, p. 95).

Esta pujanza económica ha llegado a tal grado que Salazar (2013) comenta:

El dinámico crecimiento del sur de Nayarit es resultado de las intensas campañas de promoción de los desarrollos inmobiliarios que han conurbado [sic] Puerto Vallarta y la Riviera Nayarit para convertir esta franja costera en uno de los destinos turísticos nacionales con mayor expansión y sólido futuro debido a la inversión pública y privada (p. I I8).

Hoy día, se puede enfatizar que la zona metropolitana en estudio se caracteriza por un alto crecimiento demográfico. Para ejemplificar: en el año de 2015, su tasa de crecimiento demográfico fue del 2.4\%. El crecimiento demográfico más alto se registró en la periferia, es decir, en el municipio de

5. Al tratar de planear el territorio de Puerto Vallarta y la parte sur de Nayarit, el Gobierno federal decretó la Comisión de Conurbación de la Desembocadura del Río Ameca. No obstante, dicha instancia carecía de presupuesto propio, y por esta razón y otras más se vio rebasada. 
Bahía de Banderas, cuya tasa fue del 4\%, mientras que la de Puerto Vallarta, el municipio central que dio origen a la conformación de la zona metropolitana de Puerto Vallarta, fue del $1.5 \%$. En términos absolutos, el crecimiento demográfico de la zona metropolitana se puede observar en la Tabla 3.

Tabla 3. Crecimiento demográfico en la zona metropolitana de Puerto Vallarta (1990-2015) (cantidad de habitantes)

\begin{tabular}{lllllll} 
& 1990 & 1995 & 2000 & 2005 & 2010 & 2015 \\
$\begin{array}{l}\text { Puerto } \\
\text { Vallarta }\end{array}$ & 111457 & 149876 & 184728 & 220368 & 255681 & 275640 \\
$\begin{array}{l}\text { Bahía de } \\
\text { Banderas }\end{array}$ & 39831 & 47077 & 59808 & 83739 & 124205 & 150250 \\
$\begin{array}{l}\text { Zona } \\
\text { metropolitana } \\
\text { de Puerto }\end{array}$ & 151288 & 196953 & 244536 & 304107 & 379886 & 425890 \\
Vallarta & & & & & & \\
\hline
\end{tabular}

Fuente: elaboración propia con base en Instituto Nacional de Estadística y Geografía (1990, 1995, 2000, 2005, 2010 y 2015).

Tabla 4. Tasa de crecimiento demográfico en la zona metropolitana de Puerto Vallarta (1990-2015)

\begin{tabular}{llllll} 
& $1990-$ & $1995-$ & $2000-$ & $2005-$ & $2010-$ \\
& 1995 & 2000 & 2005 & 2010 & 2015 \\
Puerto Vallarta & 5.4 & 5.0 & 3.2 & 3.0 & 1.5 \\
Bahía de Banderas & 3.0 & 5.8 & 6.1 & 8.8 & 4.0 \\
Zona metropolitana & 4.8 & 5.2 & 3.9 & 4.9 & 2.4 \\
de Puerto Vallarta & & & & & \\
\hline
\end{tabular}

Fuente: elaboración propia con base en Instituto Nacional de Estadística y Geografía (1990, 1995, 2000, 2005, 2010 y 2015).

Ahora bien, este alto crecimiento demográfico se explica en gran medida por los grandes volúmenes de inmigrantes que llegan a la zona metropolitana de Puerto Vallarta. En la Figura 2, se ilustra la procedencia y el porcentaje de los flujos migratorios que arriban al área de estudio, donde si 
bien es cierto que se da un alto volumen de desplazamientos entre los estados de Jalisco y Nayarit, también lo es que existe presencia de gente procedente de Guerrero y Chiapas, entidades federativas que se encuentran alejadas de la zona estudiada.

\section{Figura 2. Migración por residencia en la zona metropolitana} de Puerto Vallarta (2015)

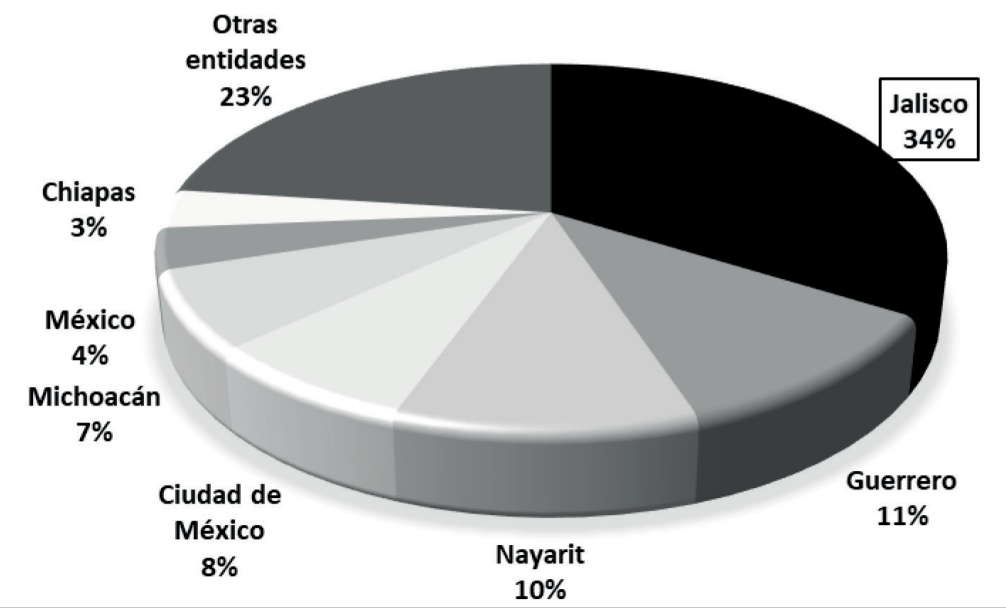

Fuente: elaboración propia con base en Instituto Nacional de Estadística y Geografía (2015). ${ }^{6}$

Además del alto crecimiento demográfico que registra esta zona por la llegada constante de inmigrantes, también se debe recalcar el arribo de turistas que la visitan anualmente. En el 2016, dicho conglomerado urbano, con 43562 cuartos de hotel, fue visitado por 5500799 turistas (Secretaría de Turismo del Estado de Jalisco, 2016; Instituto Nacional de Estadística y Geografía, 2017). Sin duda, esto dificulta la crea-

6. La información que se desprende de la Encuesta intercensal 2015 se debe tomar con cautela, pues para dar a conocer lo que acontece en el país únicamente registró los datos de 6.I millones viviendas, cuando en total son un poco más de treinta y un millones. Así pues, este instrumento es una muestra probabilística, con las cuestiones positivas y negativas que ello implica. 
ción de un sentido de pertenencia entre la población de la zona metropolitana de Puerto Vallarta, lo que es importante porque al hacer un estudio detallado de otras áreas de estudio, Lefévre enfatiza que "la falta de legitimidad proviene de dos factores: la ausencia de identidad de las áreas metropolitanas y el hecho de que no son territorios de referencia para la sociedad en conjunto" (2005, p. 221).

Ante el dinamismo demográfico de la zona metropolitana de Puerto Vallarta, y en un contexto de escasez de recursos económicos en las arcas municipales, en el año de 2010 los presidentes municipales de Puerto Vallarta y Bahía de Banderas, con el aval de sus respectivos congresos, pactaron el llamado convenio de asociación (Cárdenas, 2013), con la finalidad de: 1) crear una unidad económica y social; 2) coordinarse y asociarse para una eficaz prestación de los servicios públicos correspondientes; y 3) realizar obras de infraestructura vial, saneamiento, agua potable y alcantarillado (Castro, 2010).

De igual manera, lo anterior dio paso a la conformación de procesos de gestión y coordinación metropolitana, pues en ese mismo año los presidentes municipales también firmaron el llamado convenio de coordinación. Antes de pasar a enumerar sus logros y sus incumplimientos, es necesario recalcar la importancia de analizar a dicho territorio como una unidad económica.

2. La importancia de la zona metropolitana de Puerto Vallarta como una unidad económica

Lefévre expone que una de las justificaciones y fundamentos para que exista un Gobierno en las áreas metropolitanas es la económica, pues aparte de que esa existencia incentiva las economías de escala, da la posibilidad de encarar de mejor manera la competencia territorial que se gesta a nivel internacional (2005, pp. 198). 
Para tener una idea de la unidad económica que forman los municipios en estudio, se pueden señalar un par de hechos. El primero de ellos es que el municipio de Bahía de Banderas se vio en la necesidad de homologar el huso horario con Puerto Vallarta. Para ello, en el año 2005, los diputados federales Manuel Pérez Cárdenas y Juan Carlos Núñez Armas, de la fracción del PAN del Congreso federal, presentaron la iniciativa de reforma a la fracción II del artículo 3 de la Ley del Sistema de Horario del país ante la Cámara de Diputados del Congreso de la Unión (Cámara de Diputados, 2009). En dicha iniciativa, solicitaban sustraer al municipio Bahía de Banderas de la zona horaria Pacífico, en la cual se ubica el estado de Nayarit, para hacerlo regirse con el horario de la zona Centro, como lo hace Puerto Vallarta.

No obstante, tuvieron que pasar cuatro años para que la senadora por Jalisco Eva Contreras Sandoval presentara en sesión ordinaria de la comisión permanente la propuesta de reforma antes mencionada. El 26 de noviembre del 2009, fue aprobado el dictamen y la minuta del proyecto de decreto se remitió a la Cámara de Diputados. Esta aprobó el dictamen el 10 de diciembre de 2009, y se publicó en el Diario Oficial de la Federación el 6 de enero de 2010 (Aguilar, 2010b). El empate de horario de Bahía de Banderas con Puerto Vallarta sucedió en abril de dicho último año.

El propósito del cambio de huso horario era facilitar las actividades económicas y turísticas de ambos municipios. Un hecho que ayudó para formular y presentar dicha reforma fue la ubicación del Aeropuerto Internacional Gustavo Díaz Ordaz, en Puerto Vallarta, debido a que presta sus servicios a ambos municipios y por su ubicación se rige por el horario de la zona Centro. Eso representaba un serio inconveniente para los turistas que visitaban los destinos turísticos de Bahía de Banderas y no comprendían que estaban regidos por otro huso horario. 
Además, la propuesta estuvo avalada tanto por la población de Bahía de Banderas, que por cuestiones de trabajo cotidianamente se traslada a Puerto Vallarta, como por la Asociación de Empresarios de Bahía de Banderas (AEBBA), cuyos miembros anhelaban un mayor orden en el uso del tiempo (Asociación de Empresarios de Puerto Vallarta y Bahía de Banderas, 2017).

El segundo de los hechos que dan muestra de la conformación de una unidad económica entre los municipios de Puerto Vallarta y Bahía de Banderas es la promoción conjunta que vienen haciendo desde el 2013 por iniciativa del Gobierno federal, quien creó, junto con la participación de otros actores, una bolsa de diez millones de dólares con el objetivo de publicitar ambos paraísos en un solo destino (Huízar y Zepeda, 2013).

Sin lugar a duda, la promoción conjunta representó un logro, pues en el 2007 el Gobierno estatal de Ney González había lanzado de manera particular su marca Riviera Nayarit, mientras que el gobernador de Jalisco, Francisco Ramírez Acuña, se había negado en el 2004 a colaborar en la promoción turística común con "el argumento de que no haría una inversión millonaria para beneficiar al estado vecino de Nayarit" (Marín, 2009, p. 227).

Lo anterior se tuvo que hacer a un lado, pues al buscar la sede del Tianguis Turístico 2012, Puerto Vallarta y Bahía de Banderas trabajaron de manera conjunta. Llama la atención que en la propuesta Puerto Vallarta ofreció lugares de su infraestructura urbana, como fueron el Aeropuerto Internacional Gustavo Día Ordaz y el Centro de Convenciones, para albergar el evento, entre otros, mientras que su contraparte nayarita proporcionó una gran cantidad de instalaciones de hospedaje.

Lo interesante de la experiencia es que no solamente ambos municipios ganaron la sede, sino que obtuvieron excelentes resultados, pues se reportó la 
asistencia de 7500 personas y quinientas ochenta y seis empresas, cifra $45 \%$ superior a $20 \mathrm{II}$, asimismo asistieron representantes de treinta países, entre los que destacan Estados Unidos, Canadá, Francia, España, Italia, Bélgica, Polonia, Colombia, Brasil, Chile y Argentina. Durante el evento se registraron más de 23000 citas de negocios y la derrama ascendió a ciento cuarenta millones de pesos (Secretaría de Turismo, 2012, citado en Huízar y Zepeda, 2013, p. 25I).

Por ello, el Ejecutivo federal presentó la estrategia de apoyo al destino Puerto Vallarta- Riviera Nayarit (Huízar y Zepeda, 2013). No cabe duda que el Gobierno federal es un actor clave para impulsar la coordinación metropolitana.

Con lo anterior, queda claro que la zona metropolitana de Puerto Vallarta constituye un área económica. Ahora, el reto en términos de Lefévre es pasar a la construcción de una unidad social y política (2005, p. 198), tarea nada fácil, como se precisa a continuación.

El punto de partida para la coordinación metropolitana entre Puerto Vallarta y Bahía de Banderas sucedió en el año de 2010, cuando ambos municipios firmaron, como ya se dijo, tanto el convenio de asociación como el de cooperación. Han transcurrido ocho años del evento y resulta valido preguntarse: ¿cuáles son los logros que se han alcanzado en materia de coordinación metropolitana entre Puerto Vallarta y Bahía de Banderas? ¿Y cuáles son los incumplimientos?

\section{Logros de la coordinación metropolitana entre Puerto Vallarta y Bahía de Banderas}

Si bien es cierto que la de fondos metropolitanos es una partida federal destinada al desarrollo de las zonas metropolitanas, también lo es que la de Puerto Vallarta se ha organizado para cumplir con lo que estipulan las reglas de operación y resultar beneficiada. Por dicha razón, se considera que un logro de la coordinación metropolitana es 
la obtención de los fondos metropolitanos. En los últimos seis años, la zona en estudio ha sido acreedora de más de trescientos millones de pesos, de los cuales el $99 \%{ }^{7}$ se ha destinado al proyecto de construcción de un segundo puente sobre el río Ameca, que permitirá mayor contacto y acceso del estado de Jalisco al estado de Nayarit y viceversa. Asimismo, se construirán los accesos viales al puente. ${ }^{8}$ Como se ilustra en la Figura 3, el 1\% restante se implementó en la actualización del Plan Municipal de Desarrollo Urbano de Bahía de Banderas, Nayarit.

Figura 3. Distribución de obras y proyectos del Fondo

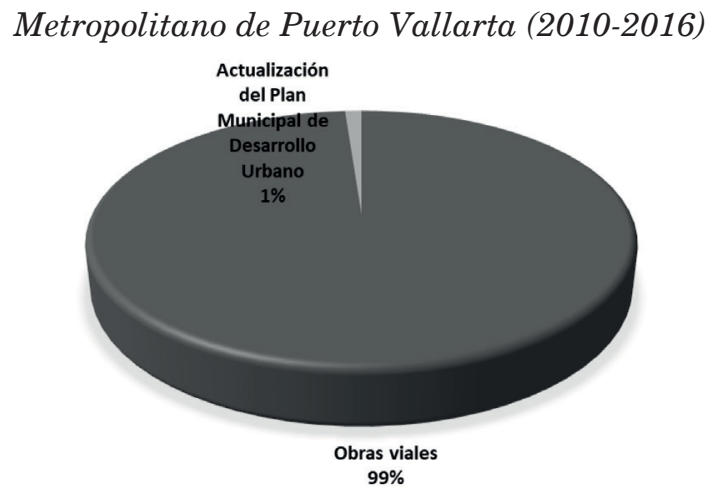

Fuente: elaboración propia con base en la información proporcionada por el Gobierno del estado de Jalisco (2016).

7. Es importante reconocer que, por su dinámica organizacional,"el encargado de gestionar y decidir sobre el destino de los fondos metropolitanos es el gobernador de la entidad donde se localiza la zona metropolitana beneficiada por los recursos económicos" (Cárdenas, 2016, p. I46). Por su parte, el Instituto de Políticas para el Transporte y el Desarrollo recalca que "las entidades dedican gran parte del año a integrar los expedientes administrativos y fiscales del proceso, prestando poca atención a la información técnica que sustente las acciones promovidas. Con ello provoca[n] la ejecución de obras que, lejos de incentivar la movilidad sustentable de las zonas metropolitanas beneficiadas con el fondo[,] inducen al uso indiscriminado del automóvil” (Orozco y Palmerín, 20I2, p. 4).

8. Cabe señalar que en el 2015 se tenía contemplado hacer estudios y un proyecto integral para desarrollar el Corredor Troncal de Transporte Público de Baja Emisión, pero este proyecto se cambió por la construcción de un entronque carretero en Cruz de Huanacaxtle-Punta Mita, en el municipio de Bahía de Banderas (Gobierno del estado de Jalisco, 2015). 
Llama la atención que en la zona de estudio no ha habido una diversificación en los rubros captados, como sí ha pasado en otras zonas metropolitanas turísticas de sol y playa en el país (Cárdenas, 2016). Por lo tanto, la población más desprotegida de esta urbe no ha resultado beneficiada por estos recursos, lo que se debe básicamente a que la gestión de los fondos metropolitanos está determinada por los Gobiernos de los estados de Jalisco y Nayarit y sus secretarías responsables de la edificación de obras públicas. En dicho mecanismo, son nulos la participación y voto de otros actores importantes que ayudarían a la conformación de contrapesos a la hora de tomar decisiones sobre el destino de dichos recursos. A pesar de ello, la Secretaría de Gobernación y el Instituto Nacional para el Federalismo y el Desarrollo Municipal consideran la implementación de dichos recursos en esta urbe como un caso exitoso (Secretaría de Gobernación e Instituto Nacional para el Federalismo y el Desarrollo Municipal, 2010, p. 86).

Cabe señalar que la implementación de la mayoría de los fondos metropolitanos en el rubro de la construcción de obras viales no es exclusiva de Puerto Vallarta, pues como lo evidenció el Reporte del Fondo Metropolitano, elaborado por el Instituto de Políticas Públicas para el Transporte y el Desarrollo (ITDP), más de 11000 millones de pesos se han destinado a obras para la movilidad del automóvil (Orozco y Palmerín, 2012, p. 35). Además, el reporte agrega que "resulta muy cuestionable, en términos de equidad, invertir la mayor parte del presupuesto público para los vehículos motorizados, cuando la mayoría de la población utiliza el transporte público, camina o anda en bicicleta" (Orozco y Palmerín, 2012, p. 18).

Lo anterior tiene estrecha relación con lo expuesto por Vicente Ugalde, quien opina que 
las prácticas cooperativas y el convenio constituyen un medio de articulación de voluntades e inercias en los múltiples polos del poder público y privado que conviven en un territorio metropolitano[,] y en consecuencia son una modalidad central en la ejecución de obras públicas (2007, p. 458).

En este caso de estudio, las obras públicas se han destinado a favorecer la movilidad motorizada y no otros medios de transporte.

\section{I Los incumplimientos en la coordinación metropolitana} entre Puerto Vallarta y Bahía de Banderas

Por principio de cuentas, se debe señalar que el objetivo del convenio de coordinación era "planear y regular conjuntamente el desarrollo urbano y regional sustentable en los municipios conurbados de Puerto Vallarta, Jalisco, y Bahía de Banderas, Nayarit" (Secretaría de Gobernación, 2012). En palabras de Lefévre, se trataría de un arreglo intermunicipal de carácter monosectorial (2005, p. 207), pero con tendencia a ser plurisectorial, debido a que planteaba varios lineamientos estratégicos, como se puede ver a continuación:

1) Zonificación primaria: que corresponde a la clasificación de áreas y a la definición de la utilización general del suelo;

2) Definición de las reservas urbanas;

3) Conservación: de las zonas agrícolas, así como las zonas protegidas y las de valor natural o paisajístico;

4) Infraestructura vial: que comprende los caminos regionales (carreteras), los libramientos urbanos y las vialidades primarias intermunicipales;

5) Movilidad y transporte: con el objetivo de propiciar el traslado ágil y seguro de las personas;

6) Infraestructura de agua y saneamiento: con el objetivo de establecer un sistema conurbado de abastecimiento y tratamiento del agua en la zona; 
7) Servicios turísticos: para contribuir a una visión a largo plazo que garantice el desarrollo sustentable (Secretaría de Gobernación, 2012). ${ }^{9}$

Después de firmar el convenio de cooperación, el siguiente paso fue la constitución de la Comisión de Conurbación entre Puerto Vallarta y Bahía de Banderas, integrada por un presidente, un vicepresidente, un vocal ejecutivo, dos secretarios técnicos y dos vocales (Secretaría de Gobernación, 2012). Este fue un hecho significativo, pero al no definirse la estructura ni el financiamiento, el ejercicio se vio limitado.

Ahora bien, se debe recordar que "la tarea principal de las comisiones de las conurbaciones consiste en elaborar el Programa de Ordenamiento Urbano de la Región Conurbada, y con base en este formular los programas denominados integrales y estratégicos relativos a varios temas" (Iracheta, 2012, p. 74) ${ }^{10}$ Lo anterior sucedió para la zona metropolitana de Puerto Vallarta en el año de 2012, cuando se formuló el Programa de Ordenamiento de la Zona Metropolitana Interestatal de Puerto Vallarta-Bahía de Banderas, promovido por la Secretaría de Desarrollo Social a través de la coordinación de Nora Bringas y Basilio Verduzco. En dicho documento, se planteó la necesidad de atender la diversidad de usos de suelo, su redensificación y mixtura (Bringas y Verduzco, 2012), así como atender los lineamientos estratégicos ya mencionados.

El esfuerzo por regular y planear el desarrollo urbano de ambos municipios quedó en el papel, pues al tratar de

9. Otro ejercicio similar ocurrió en el año de 2004, cuando Puebla y Tlaxcala firmaron el convenio de coordinación para planear y regular el desarrollo urbano de su zona metropolitana. El objetivo del convenio es la planeación y regulación, conjunta y coordinada, del desarrollo urbano y regional sustentable en los municipios conurbados (Iracheta, 2012, p. 74).

10. En el convenio de coordinación de la zona en estudio, quedó establecida la creación de un programa en la cláusula segunda (Secretaría de Gobernación, 2012). 
darle seguimiento institucional al programa, la respuesta que ofreció la Secretaría de Desarrollo Agrario, Territorial y Urbano por vía transparencia fue que

El Plan de Ordenamiento de la Zona Metropolitana Interestatal de PuertoVallarta y Bahía de Banderas [,] coordinado por el doctor Basilio Verduzco y la doctora Nora Bringas[,] sólo se concluyó en su elaboración[,] sin que este se aprobara por los cabildos correspondientes, se publicara o inscribiera, por lo tanto no alcanzó a adquirir su plena [sic] legal establecida para este tipo de programas (Sistema virtual dependiente del Instituto Nacional de Transparencia,Acceso a la Información y Protección de Datos Personales, 2015).

Dicho plan era interesante porque identificaba que las principales problemáticas que enfrenta la zona eran:

a) Concentración de flujos de transporte terrestre en tres accesos principales que convergen en un mismo eje troncal.

b) Saturación de vías de comunicación terrestre en las áreas aledañas al aeropuerto internacional, la terminal marítima y la central de autobuses.

c) Presión sobre áreas de montaña para la apertura y/ o ampliación de libramientos carreteros o vías de acceso a la ciudad, con las consecuencias que tendría[n] en su entorno dichas vías.

d) Presión sobre el territorio asociada a la conversión de suelos agrícolas y de montaña para fines turísticos y recreativos.

e) Construcción de viviendas en tierras agrícolas.

f) Ocupación informal del suelo en zonas vulnerables expuestas a inundaciones y deslaves.

g) Conversión de suelos forestales en zonas agrícolas o en asentamientos turísticos campestres.

h) Contaminación por disposición clandestina de desechos y aguas residuales, y mayores presiones sobre recursos naturales valiosos, incluyendo el uso de arenas y minerales para la construcción y agua 
para abastecer a una población en crecimiento (Bringas y Verduzco, 2012, pp. 14 y I5).

Así, pues, uno de los principales desafíos de la zona metropolitana de Puerto Vallarta es la falta de elaboración y aplicación de un plan que regule su ordenamiento territorial, y esto obedece a muchas razones, una de las cuales son los intereses que guarda el capital inmobiliario-financiero en la zona, lo que se puede observar claramente en el caso de Bahía de Banderas (Cárdenas, 2015).

Dado lo anteriormente expuesto, se está de acuerdo con Iracheta (2012) cuando menciona que

El sistema de la experiencia de la planeación en la metrópoli ha sido decepcionante. En su mayor parte, los planes han servido para que los actores con poder definan usos del suelo, de acuerdo a sus propios intereses, ante la complacencia de las autoridades y la inoperancia de los instrumentos de control en la planificación urbana y regional (p. 72).

Otro de los temas álgidos en materia de coordinación metropolitana ha sido el de la movilidad urbana, que resulta vital resolver porque involucra tanto a habitantes como a turistas. Respecto a la problemática del transporte en la zona metropolitana de Puerto Vallarta, el programa de ordenamiento, considera que este

se liga directamente con el problema vial en tanto la falta de una red de vialidades primarias inhibe la estructuración de una red troncal de rutas de transporte, que permita traslados eficientes, unidades $y$ puntos de ascenso y descenso confortables, seguros y de bajo costos. Sin embargo, el sistema de transporte tiene sus propios problemas de carácter organizacional, político y legal que deben ser resueltos para darle la funcionalidad a la metrópoli (Bringas y Verduzco, 20I2, p. 37). 
Son varias las voces que han señalado lo deficiente que resulta el transporte en la zona metropolitana de Puerto Vallarta, y de ahí la necesidad de encontrar algunas soluciones. Por ejemplo, en el marco de la inauguración del Consejo de Desarrollo Metropolitano entre Bahía de Banderas y Puerto Vallarta, el entonces secretario general de Gobierno de Nayarit, Roberto Mejía Pérez, habló de la importancia de concluir con el problema de los camiones y taxistas en la zona conurbada de Nayarit y Jalisco (Moguel, 2010).

De igual manera, Rafael Yerena Zambrano, dirigente estatal de la Confederación de Trabajadores de México (CTM), informó que "atender la movilidad urbana es un tema prioritario y se espera que antes de que finalice el 2010 deberán sentarse las bases para la operación de un sistema de transporte urbano intermunicipal, con una cobertura Punta Mita-Boca de Tomatlán, Jalisco" (Lira, 2010a).

Por su parte, el entonces (2010) gobernador de Nayarit, Ney González, recalcó que era indispensable contar con un nuevo sistema de transporte con el objetivo de articular la conurbación (Aguilar, 2010a), mientras que a su vez el entonces presidente municipal de Bahía de Banderas, Héctor Paniagua, lamentó que el transporte siga siendo de “carritos viejos" en la zona. Él propuso que se deben sentar las bases entre las dos ciudades de la zona con la finalidad de contar con un transporte homologado, moderno y con tarifas adecuadas (Lira, 2010b).

Al parecer, la problemática se centra del lado de Puerto Vallarta, Jalisco, porque Raúl de los Santos, dirigente estatal de la fundación Alianza de Camioneros y Automovilistas de Servicio Público en el Estado de Nayarit (ACASPEN) aseguró que "el Gobierno de Nayarit y las organizaciones transportistas de Bahía de Banderas están preparadas, sólo falta que el Gobierno de Jalisco se ponga de acuerdo con los transportistas de Puerto Vallarta para [que] la conurbación 
del transporte entre ambos municipios sea una realidad" (Aguilar, 2010c).

Un aspecto sobre el tema del transporte público que habría que señalar es la puesta en marcha del proyecto del transporte público Búho Nocturno, en Puerto Vallarta, en el mes de noviembre de 2011. El transporte presta sus servicios de las 23:00 a las 5:00 horas. Los beneficiados de esta iniciativa han sido los trabajadores, que reportan ahorros hasta por un 400\% (Sánchez, 2013, p. 48).

Años después del 2010, se han observado algunos avances en materia del transporte conurbado. Uno de ellos fue que el tema del transporte público entró en la agenda pública. Así, pues, en 2013, se reunieron las autoridades de los dos estados, empresarios y hoteleros (Álvarez, 2013). En dicha reunión, se hizo la petición de que el Gobierno del estado de Jalisco retirara de circulación los camiones del Sistema de Transporte Colectivo de la Zona Metropolitana (Sistecozome) (Álvarez, 2013). ${ }^{11}$ Cabe mencionar que dichos camiones prestan el servicio en malas condiciones, lo que es una queja recurrente de los usuarios, además de que por su estado de obsolescencia deterioran la imagen del destino turístico internacional.

No obstante, para el 2014, varios medios locales recalcaron que estaba por terminar la administración municipal de Bahía de Banderas e iba a la mitad de su periodo la de Puerto Vallarta, y aún no había avances claros del proyecto de conurbación de los dos destinos turísticos de Jalisco y Nayarit. Entre los temas que quedaron completamente atorados estuvo el de la regulación del transporte público, donde los intereses de los permisionarios chocaron constantemente, y ni siquiera los gobernadores tuvieron poder suficiente para someterlos (Ortiz, 2014).

II. No se conocieron los acuerdos a los que se llegó en la reunión, y al tratar de solicitar dicha información vía el sistema Infomex, la respuesta que ofreció la Unidad de Transparencia de la Secretaría de Movilidad fue que no se localizó la información al respecto (Infomex y Secretaría de Movilidad de Jalisco, 2015). 
Por su parte, a finales de 2014 el entonces secretario de Movilidad de Jalisco, Mauricio Gudiño, informó que los transportistas se habían puesto la camiseta para dar paso a una o dos nuevas empresas que vendrían a modernizar la imagen y calidad del servicio, lo que posicionaría a Puerto Vallarta como pionero nacional (Lira, 2014). ${ }^{12}$ Sin embargo, al darle seguimiento a la información de la nota, el sistema Infomex señaló que la Secretaría de Movilidad no contaba con información al respecto (Infomex y Secretaría de Movilidad de Jalisco, 2015).

Bajo este contexto, se ignora cuáles son los avances en materia de transporte intermunicipal en la zona de estudio, cuando el asunto resulta apremiante de resolver. En este contexto, se debe traer a colación el comentario de Lefévre cuando expone que para generar responsabilidad en las áreas metropolitanas es indispensable que "las actividades y políticas de los acuerdos de gobernabilidad metropolitana puedan ser analizadas por los ciudadanos [,] y que las preguntas de estos deben ser respondidas" (2005, p. 254). Por su parte, Rojas (2005) considera que es importante tener Gobiernos transparentes, porque se "fomenta la participación de la comunidad en las decisiones y en la solución de problemas" (p. 49). Mientras tanto, en Puerto Vallarta continúa la problemática: 1) las redes de transportes son poco funcionales; 2) la estructura de organización de las empresas es poco eficiente; y 3) hay conflictos entre prestadores de servicios (Verduzco, 2013, p. 259).

Otra de las prioridades en el tema de la conurbación entre Puerto Vallarta y Bahía de Banderas es el de la

12. Mauricio Gudiño recalcó que en Puerto Vallarta había un padrón de cuatrocientos cincuenta permisionarios, con más de ciento cincuenta concesiones. Se esperaba que con el nuevo esquema de transporte en Puerto Vallarta el número de permisionarios se redujera de cuatrocientos cincuenta a trescientos (Lira, 20I4). Asimismo, el funcionario público enfatizó que el nuevo esquema de transporte vendría aparejado con cursos de capacitación, renovación de camiones, uniformes, cámaras de vigilancia y sistema GPS en las unidades (Lira, 20/4).

\section{6}


seguridad pública, necesaria para mantener en paz y en calma a la zona (García, 2014). Al respecto, Miguel González Campeón, Luis Carlos Nájera y Jorge Alonso Campos Huerta, funcionarios públicos encargados de velar por la seguridad pública de la zona hacia el año 2014, señalaron que habían avanzado en el tema en la región, pero aún no tenían el éxito deseado. Recalcaron: "Hay voluntad. No hay fecha establecida para que el documento de conurbación en seguridad sea firmado" (Lira, 2013).

Se debe enfatizar que la cuestión de la seguridad se vuelve primordial de atender en una zona metropolitana de carácter interestatal porque quienes delinquen en Jalisco escapan a Nayarit y viceversa, sin que exista un protocolo de coordinación (Lira, 2013).

Otros temas centrales en la coordinación metropolitana son el saneamiento y el tratamiento de aguas residuales y la recolección de residuos sólidos. Al respecto, el programa de ordenamiento menciona que:

La zona metropolitana tiene problemas asociados con el manejo de desechos, el tratamiento de aguas, la explotación de mantos freáticos, el cambio de usos de suelo en zonas forestales para fines turísticos, agrícolas y urbanos, y la contaminación de agua, dado que año con año surgen reportes de contaminación de playas[,] sobre todo las cercanas al centro y sur de Puerto Vallarta (Bringas y Verduzco, 20I2, p. 54).

No cabe duda que la zona metropolitana de Puerto Vallarta vive de los recursos naturales que ofrece al visitante, y si estos no se respetan y preservan, queda en duda de qué vivirán, en el corto, mediano y largo plazo, los habitantes de un área que tiene como vocación económica el turismo de sol y playa.

De igual manera, es importante señalar que el programa de ordenamiento considera que "hace falta un organismo que se encargue del tratamiento de las aguas negras, así como del suministro del agua en toda la metrópoli. Se reconoce 
que para ello se tendría que crear un marco legal que sirva para la metropolización" (Bringas y Verduzco, 2012, p. 30).

Expuesto lo anterior, se observa que la zona metropolitana de Puerto Vallarta enfrenta serias dificultades. Una vez más, se presenta que en la administración y el gobierno de una zona metropolitana del país están presentes la cooperación, la indiferencia y el conflicto (Zentella, 2005, p. 260). Una propuesta para superar lo antes mencionado es darles obligatoriedad a los acuerdos ya consensados, lo que no es fácil, pues se trata de gestionar y coordinar una zona metropolitana de carácter interestatal, donde la normatividad, los calendarios y los signos partidistas representan serios obstáculos para el adecuado funcionamiento y desarrollo de una propuesta de acuerdo (Iracheta, 2012, p. 73). Además, entre sus habitantes no existe un sentimiento de pertenencia que ayude a conformar una unidad social y a que se busquen las soluciones en conjunto (Baños, 2013).

En este sentido, se está de acuerdo con Ward cuando afirma que "México todavía está lejos de crear estructuras representativas y participativas de gobierno efectivas para el ámbito metropolitano" (2011, p. 241). A pesar de que se han dado pasos significativos, como la coincidencia en la necesidad de negociación o la formalización de un convenio de coordinación (Ugalde, 2007, p. 458), hace falta darle obligatoriedad y continuidad al mismo. Ante esto, una de las propuestas, según Lefévre, es la "creación de cualquier tipo de acuerdo de gobernabilidad de ámbito metropolitano y hacerlo explicable con instrumentos de responsabilidad" (2005, p. 257). Al parecer, en el corto, mediano y largo plazo no se cumplirán las expectativas de los pobladores que aspiran a alcanzar una mejor calidad de vida. 


\section{Conclusión}

A lo largo del documento, se abordó la importancia que cobra hoy día el fenómeno metropolitano en nuestro país, donde no existe un marco institucional que abone al entendimiento y solución de los problemas que dicho fenómeno genera. Se señaló que un hecho significativo acaeció en el 2004, cuando organismos institucionales definieron y delimitaron las zonas metropolitanas con que cuenta México. Así, se determinó a la zona metropolitana de Puerto Vallarta como una de ellas, conformada por los municipios de Puerto Vallarta, Jalisco, y Bahía de Banderas, Nayarit. Se confirmó su carácter interestatal, que tiene como vocación económica el turismo de sol y playa, y que posee un alto crecimiento demográfico.

El artículo señaló que esta zona, en los últimos años, ha trabajado como una unidad económica. Se detalló el ejemplo más importante de ello: el municipio de Bahía de Banderas empató su huso horario con el de Puerto Vallarta. De igual manera, se dijo, los municipios integrantes han hecho promoción turística de manera conjunta desde el 2013, hecho en que se constata la importancia de unir esfuerzos para sacar el máximo provecho en un contexto de gran competitividad.

Ahora bien, sobre los logros en materia de coordinación metropolitana, se señaló en primer lugar el hecho de haber concretado la realización de un convenio de coordinación, el cual fue firmado por los tres órdenes de Gobierno en el 2010. También se especificó que un primer beneficio de este convenio fue bajar recursos de los fondos metropolitanos por más de trescientos millones de pesos en los primeros seis años. Como se dijo, todos los recursos se han destinado a obras viales, sobre todo a la realización de un segundo puente para conectar a Puerto Vallarta con Bahía de Banderas.

También, en el presente artículo se detallaron los incumplimientos. Estos son más numerosos, pues hizo falta darle 
legalidad al Programa de Ordenamiento de la Zona Metropolitana Interestatal de Puerto Vallarta-Bahía de Banderas, promovido por la Secretaría de Desarrollo Social y coordinado por Nora Bringas y Basilio Verduzco. En dicho documento, se buscó planear y regular conjuntamente el desarrollo urbano y regional sustentable de ambos municipios. Aunque pareciera que este mecanismo de coordinación es de carácter monosectorial, en sus lineamientos específicos se establece también como prioritario atender la seguridad y el transporte públicos, el saneamiento y tratamiento de aguas residuales y la actividad turística, lo que lo hace plurisectorial.

Como se dijo, el programa quedó en papel, a pesar de las voces de empresarios y de los mismos funcionarios públicos en turno, que demandan encontrar soluciones a los problemas que atañen a la zona. Pareciera que sólo hace falta voluntad para darle obligatoriedad y continuidad a los acuerdos ya pactados, tarea nada fácil cuando se interponen normatividades distintas, calendarios electorales dispares, diferencias entre los tomadores de decisión por no pertenecer al mismo partido político, así como una diversidad de actores con intereses no comunes. Así pues, en este contexto adverso, es difícil hablar de gobernabilidad en la zona metropolitana de Puerto Vallarta.

Bibliografía

\section{0}

Aguilar, P. (07 de marzo de 2010a). "La columna vertebral de la conurbación es el transporte: Ney González". NoticiasPV. Recuperado de: www.noticiaspv.com/lacolumna-vertebral-de-la-conurbación-es-el-transporteney-gonzalez/

Aguilar,P. (19 de marzo de 20 I0b)."Bahía con horario central a partir del 4 de abril de 2010". NoticiasPV. Recuperado de: www.noticiaspv.com/bahia-con-horario-central-apartir-del-4-de-abril/

Aguilar, P. (09 de diciembre de 2010c). "Transporte público conurbado se hará realidad bajo nuevo esquema: Ney 
González". NoticiasPV. Recuperado de: http://www. Bibliografía noticiaspv.com/transporte-publico-conurbado-se-hararealidad-bajo-nuevo-esquema-ney-gonzalez/

Álvarez, F. (30 de agosto de 20I3). "Buscarán consensos y acciones en tema del transporte público". Vallarta Opina. Recuperado de: http://vallartaopina.net/2013/08/30/ local/ciudad/buscaran-consensos-y-acciones-en-tema-del-transporte-publicol

Arellano, A. (2013a). "Las instituciones metropolitanas de Guadalajara”, en R. Arias (Coord.), Coordinación metropolitana y gestión pública municipal (pp. 7I-98). Zapopan: El Colegio de Jalisco.

Arellano, A. (20I3b). La gestión metropolitana. Casos y experiencias de diseño institucional. México:UNAM-IIJ, El Colegio de Jalisco.

Arias, R., y Arellano, A. (20I3). "El área metropolitana de Guadalajara: travesía urbana, política y gestión metropolitana", en A.Arellano, e I. Ortiz (coords.), Coordinación y gestión metropolitana en Jalisco (pp. 27-59). PuertoVallarta: Universidad de Guadalajara.

Asociación de Empresarios de Puerto Vallarta y Bahía de Banderas (2017). "Historia de la asociación de empresarios AEBBA". AEBBA. Recuperado de: http://asociacionde-empresarios-aebba.com/historia-aebba/

Baños,A. (2013). “Consideraciones sobre la gestión metropolitana en México. Acercamientos al caso de la Bahía de Banderas". Trace, 64, 69-87.

Baños,A., Muñoz, M., y Tovar, R. (s/f). El turismo y el desarrollo urbano-regional en la región metropolitana de la Bahía de Banderas [manuscrito en prensa].

Barrón, C. (coord.) (s/f). "Bahía de Banderas". Enciclopedia de los municipios y delegaciones de México [archivos de enciclopedia en línea]. Recuperado de: http://www. inafed.gob.mx/work/enciclopedia/EMMI8nayarit/ municipios//8020a.html 
Bibliografía
Bringas, N., y Verduzco, B. (20 I 2). Programa de ordenamiento de la zona metropolitana interestatal de Puerto VallartaBahía de Banderas. Tijuana: SEDESOL, El Colegio de la Frontera Norte.

Cámara de Diputados (I0 de diciembre de 2009). “Dictamen de la Comisión de Energía a la minuta proyecto de decreto que reforma la fracción II del artículo 3 de la Ley del Sistema de Horario de los Estados Unidos Mexicanos". Gaceta Parlamentaria. Recuperado de: http://gaceta.diputados.gob.mx/Gaceta/6I/2009/ $\mathrm{dic} / 2009$ I 2 I0-IV.html

Cámara de Diputados (2016). Ley General de Asentamientos Humanos, Ordenamiento Territorial y Desarrollo Urbano. Recuperado de: http://www.diputados.gob.mx/LeyesBiblio/pdf/LGAHOTDU_28I I I6.pdf

Cárdenas, E. (20/3). "La zona metropolitana de Puerto Vallarta y su convenio de asociación intermunicipal", en R.Arias (coord.), Coordinación metropolitana y gestión pública municipal (pp. 99-II8). Zapopan: El Colegio de Jalisco.

Cárdenas, E. (20I4).“Dinámicas demográficas en tres zonas metropolitanas de México:Acapulco, Cancún y Puerto Vallarta". Espacios públicos, (40), 69-94.

Cárdenas, E. (20I5). “Actores en el desarrollo urbano". Ciudades, (I06), 37-44.

Cárdenas, E. (2016). "Los fondos metropolitanos en tres áreas urbanas: Acapulco, Cancún y Puerto Vallarta”. Revista Provincia, (36), | 37-I7I.

Castro, F. (20I0). "Propuesta de convenio de colaboración que elaboró y sometió al pleno del Ayuntamiento de Puerto Vallarta" [en prensa].

Cerrillo, A. (2005). “La gobernanza hoy: introducción”, en A. Cerrillo (coord.), La gobernanza hoy: 10 textos de referencia (pp. I I-36). Madrid: Instituto Nacional de Administración Pública. 
César, A., y Stella, A. (coords.) (200I). Bahía de Banderas a futuro, construyendo el porvenir 2000-2025. PuertoVallarta: Universidad de Guadalajara.

César, F. (2007). Ciudades turísticas. Desarrollo e imaginarios Careyes y Nuevo Vallarta. Puerto Vallarta: Universidad de Guadalajara.

Constitución Política de los Estados Unidos Mexicanos (2014). México: Editorial Porrúa.

Fideicomiso para el Desarrollo de la Región Centro Occidente (2009). Diagnóstico del Programa de ordenamiento de la zona metropolitana interestatal de Puerto Vallarta-Bahía de Banderas. Guadalajara: FIDERCO.

García, E. (25 de febrero de 20l4). "Seguridad en la región exige más coordinación de Vallarta con Bahía". Vallarta Opina. Recuperado de: http://vallartaopina. net/20 I 4/02/25/local/ciudad/seguridad-en-la-regionexige-mas-coordinacion-de-vallarta-con-bahia/

Gobierno del estado de Jalisco (20I5). Comité técnico de evaluación de proyectos del fideicomiso público de administración e inversión del Fondo Metropolitano Puerto Vallarta. Recuperado de: https://transparencia.info.jalisco.gob.mx/ sites/default/files/l Sesión Ordinaria Comité 20I5.pdf

Gobierno del estado de Jalisco (2016). Comité técnico de evaluación de proyectos del fideicomiso público de administración e inversión del Fondo Metropolitano Puerto Vallarta. Recuperado de: https://transparencia.info.jalisco.gob.mx/ sites/default/files/I.SesiónOrdinariaComitéTécnicoPV. pdf

H. Ayuntamiento de Puerto Vallarta (s/f). "Puerto Vallarta". Enciclopedia de los municipios y delegaciones de México [archivos de enciclopedia en línea]. Recuperado de: http://siglo.inafed.gob.mx/enciclopedia/EMMI4jalisco/ municipios/ I 4067a.html

Huízar, M., y Zepeda, S. L. (20I3). “La estrategia de promoción conjunta Puerto Vallarta-Riviera Nayarit: entre la 
competencia y la colaboración", en Comité Directivo de la Red Nacional de Administración y Negocios (coord.), Estudios en torno a los negocios mexicanos: competitividad y desarrollo organizacional (pp. 245-258). México: REDAYN. Recuperado de: https://www.researchgate.net/ publication/279561932_LA_ESTRATEGIA_DE_PROMOCION_CONJUNTA_PUERTO_VALLARTA_RIVIERA_NAYARIT_ENTRE_LA_COMPETENCIA_Y_ LA_COLABORACION

Infomex,y Secretaría de Movilidad de Jalisco (20I5). Número de expediente 282/2015 [en poder de la autora]. Instituto Nacional de Estadística y Geografía (1990). Censo general de población y vivienda. Recuperado de: http:// www.inegi.org.mx/lib/Olap/consulta/general_ver4/ MDXQueryDatos.asp?\#Regreso\&c $=$ | | 894 Instituto Nacional de Estadística y Geografía (1995). Conteo de población y vivienda. Recuperado de: http://www.inegi. org.mx/lib/Olap/consulta/general_ver4/MDXQueryDatos.asp?\#Regreso\&c = I | 884

Instituto Nacional de Estadística y Geografía (2000). Censo general de población y vivienda. Recuperado de: http:// www.beta.inegi.org.mx/proyectos/ccpv/2000/default. html

Instituto Nacional de Estadística y Geografía (2005). Conteo de población y vivienda. Recuperado de: http://www.inegi. org.mx/lib/Olap/consulta/general_ver4/MDXQueryDatos.asp?\#Regreso\&c $=\mid 7352$

Instituto Nacional de Estadística y Geografía (20 I0). Censo general de población y vivienda. Recuperado de: http:// www.inegi.org.mx/lib/olap/consulta/general_ver4/ MDXQueryDatos.asp?\#Regreso\&c $=27770$

Instituto Nacional de Estadística y Geografía (20 I4a).Zonas metropolitanas de los Estados Unidos Mexicanos. Recuperado de: http://internet.contenidos.inegi.org.mx/contenidos/Productos/prod_serv/contenidos/espanol/bvi- 
negi/productos/nueva_estruc/CE_20I4/702825087227. pdf

Instituto Nacional de Estadística y Geografía (2014b). Marco geoestadístico 2014 versión 6.2 (DENUE 0I/20/5). Recuperado de: http://www.beta.inegi.org.mx/app/biblioteca/ ficha.html?upc $=702825004386$

Instituto Nacional de Estadística y Geografía (2015). Encuesta intercensal. Recuperado de: http://www.beta.inegi.org. $\mathrm{mx} /$ proyectos/enchogares/especiales/intercensal/

Instituto Nacional de Estadística y Geografía (20I7). Anuario estadístico y geográfico de Nayarit, 20 I 7. Recuperado de: www.datatur.sectur.gob.mx/ITXef_Docs/NAY_ANUARIO_PDF.pdf

Iracheta, A. (2003).“Gobernabilidad en la zona metropolitana delValle de México". Papeles de población, 9(36), 21 I-239. Recuperado de: www.redalyc.org/pdf/ I I / I I 203609.pdf Iracheta, A. (2010)."El fenómeno metropolitano en México”. Economía y sociedad, XIV(25), I53-I79.

Iracheta, A. (20I2). Metrópolis en crisis. Una propuesta para la zona metropolitana Puebla-Tlaxcala. Zinacantepec: El Colegio Mexiquense, Instituto de Ciencias Sociales y Humanidades, BUAP.

Iracheta, A., e Iracheta, J. (20I4). Evaluación de los fondos metropolitano y regional del Gobierno federal mexicano. México: CIDE-Centro CLEAR para América Latina, SHCP$B I D$, Colegio Mexiquense, Centro Eure.

Jiménez, A. (1993). Turismo. Estructura y desarrollo. La estructura funcional del turismo internacional y la política turística de México. Desarrollo histórico. 1945-1990. México: McGraw-Hill.

Lefévre, C. (2005).“Gobernabilidad democrática de las áreas metropolitanas. Experiencias y lecciones internacionales para las ciudades latinoamericanas”, en E. Rojas, J. R. Cuadrado Roura, y J. M. Fernández (eds.), Gobernar las 
metrópolis (pp. 195-262).Washington: Banco Interamericano de Desarrollo.

Lira, M. (2I de mayo de 20I0a)."Busca establecer el transporte urbano intermunicipal PV-Bahía”. NoticiasPV. Recuperado de: http://noticiaspv.com/buscan-establecer-eltransporte-urbano-intermunicipal-pv-bahia/

Lira, M. (I 2 de diciembre de 20 I Ob)."Inconcebible siglo XXI sin conurbación en transporte”. NoticiasPV. Recuperado de: http://noticiaspv.com/inconcebible-siglo-xxi-sinconurbacion-en-transporte/

Lira, M. (2I de junio de 20I3)."Sin éxito conurbación Jalisco Nayarit en seguridad". NoticiasPV. Recuperado de: http:// www.noticiaspv.com/sin-exito-conurbacion-jalisconayarit-en-seguridad/

Lira, M. (I3 de noviembre de 20I4). “Desaparecerán unión de permisionarios y alianza de transportistas". NoticiasPV. Recuperado de:http:// www.noticiaspv.com/desapareceran-union-de-permisionarios-alianza-de-transportistas

López Portillo,J. (09 de enero de 1978).“Decreto por el que se declara zona conurbada la comprendida por el área circular generada por un radio de 30 kilómetros, cuyo centro está constituido por el punto de intersección de la línea fronteriza entre los estados de Jalisco y Nayarit, y de la línea que resulte de unir la cabecera municipal del municipio de Puerto Vallarta, Jal., con el centro de población La Jarretadera, del municipio de Compostela, Nay.". Diario Oficial de la Federación. Recuperado de: http://www.dof.gob.mx/nota_detalle.php?codigo $=467$ 4349\&fecha $=09 / 01 / 1978$

Marín, G. (2009). “Turismo, globalización y desarrollo local: PuertoVallarta y los retos de porvenir”. Estudios demográficos y urbanos, 24(I), 219-297.

Mayntz, R. (2005).“Nuevos desafíos de la teoría de la gobernanza", en A. Cerrillo (coord.), La gobernanza hoy: 10 
textos de referencia (pp.83-98). Madrid: Instituto Nacional Bibliografía de Administración Pública.

Moguel, L. (26 de marzo de 2010).“"Buscan terminar conflictos de transporte Bahía de Banderas y Vallarta". NoticiasPV. Recuperado de: http://noticiaspv.com/buscan-terminarconflicto-de-transporte-bahia-de-banderas-y-vallarta/

Navarro, L., y Gómez, A. (2009). "Población y poblamiento en el municipio de Bahía de Banderas”, en P. Núñez, y R. Rodríguez (coords.), Sociedad y economía. Estudios sobre Puerto Vallarta y su región (pp. 233-249). Puerto Vallarta: Universidad de Guadalajara.

Orozco, M.,y Palmerín,A. (20I2)."Reporte de la gestión del fondo metropolitano". Instituto de Políticas para el Transporte y el Desarrollo. Recuperado de: http://mexico.ITDP. org/wp-content/uploads/Reporte-Fondo-Metropolitano Ortiz, E. (06 de mayo de 20I4). "Lento, el avance en los trabajos para la conurbación PV-Bahía”. Vallarta Opina. Recuperado de: http://vallartaopina.net/2014/06/05/ local/ciudad/lento-el-avance-en-los-trabajos-para-laconurbacion-pv-bahia/

Peters, G., y Pierre, J. (2005). "Por qué ahora el interés de la gobernanza”, en A. Cerrillo (Coord.), La gobernanza hoy: 10 textos de referencia (pp. 37-56). Madrid: Instituto Nacional de Administración Pública.

Plascencia,A. (05 de noviembre de 20I2). “Los excesos de los González Reséndiz”. Reporte Índigo. Recuperado de: http://www.reporteindigo.com/reporte/los-excesos-degonzalez-resendiz/

Prats, J. (2005). "Modos de gobernación de las sociedades globales", en A. Cerrillo (coord.), La gobernanza hoy: 10 textos de referencia (pp. 145-I72). Madrid: Instituto Nacional de Administración Pública.

Programa de las Naciones Unidas para los Asentamientos Humanos, y Secretaría de Desarrollo Social (20II). Estado de las ciudades de México. México: ONU-HABITAT, 
Bibliografía
SEDESOL. Recuperado de: http://bibliotecadigital.imipens. org/uploads/Estado\%20de\%20las\%20Ciudades\%20deMexico\%2020I0-20I I\%20-\%20SEDESOL.pdf

Ramírez, J. (1999)."Gobernabilidad y ciudadanía política en las áreas metropolitanas”. Espiral Estudios sobre Estado y sociedad, VI(16), I87-225. Recuperado de: http:// www.espiral.cucsh.udg.mx/index.php/EEES/article/ view/II 3 I// 036

Rhodes, R. (2005). "La nueva gobernanza: gobernar sin gobierno”, en A. Cerril lo (Coord.), La gobernanza hoy: 10 textos de referencia (pp. 99-122). Madrid: Instituto Nacional de Administración Pública.

Rojas, E. (2005). “Las regiones metropolitanas de América Latina. Problemas de desarrollo y gobierno”, en E. Rojas, J. R. Cuadrado, y J. M. Fernández (eds.), Gobernar las metrópolis (pp. 35-54). Washington: Banco Interamericano de Desarrollo.

Salazar, A. (20I3). "Dinámicas sociopolíticas del turismo internacional y las segundas residencias en la Riviera Nayarit", en C. Oehmichen (ed.), Enfoques antropológicos sobre el turismo contemporáneo (pp. I I I-138). México: Universidad Nacional Autónoma de México, Instituto de Investigaciones Antropológicas.

Salinas, L. A. (2017). "Gestión metropolitana en la zona metropolitana delValle de México: entre la legalidad y la voluntad política". Papeles de población, 23(9I), I43-I69. Recuperado de:www.rppoblacionuaemex/pp/indez.php/ papelesdepoblacion/article/dowload/pdf

Sánchez, B. (20|3). Implementación del transporte público denominado "búho nocturno" en el área metropolitana de Guadalajara y Puerto Vallarta (tesis de maestría inédita). ITESO:Tlaquepaque.

Secretaría de Desarrollo Social, Consejo Nacional de Población, e Instituto Nacional de Estadística y Geografía 
(2004). Delimitación de las zonas metropolitanas de México Bibliografía 2000. Aguascalientes: SEDESOL, CONAPO, INEGI.

Secretaría de Desarrollo Social, Consejo Nacional de Población, e Instituto Nacional de Estadística y Geografía (2012). Delimitación de las zonas metropolitanas de México 2010. Aguascalientes: SEDESOL, CONAPO, INEGI.

Secretaría de Gobernación (14 de septiembre de 2012). "Convenio de coordinación para planear y regular conjuntamente el desarrollo urbano y regional sustentable en los municipios conurbados de PuertoVallarta,Jalisco y Bahía de Banderas, Nayarit, que celebran la Secretaría de Desarrollo Social, los estados de Jalisco y Nayarit y los municipios de PuertoVallarta y Bahía de Banderas". Diario Oficial de la Federación. Recuperado de: http:// www.dof.gob.mx/nota_detalle.php?codigo $=52682 \mathrm{I} 7 \& \mathrm{f}$ echa $=\mid 4 / 09 / 2012$

Secretaría de Gobernación, e Instituto Nacional para el Federalismo y el Desarrollo Municipal (20I0). Impacto del fondo metropolitano. México: SEGOB, INAFED.

Secretaría de Turismo del Estado de Jalisco (2016). "Anuario 2016". Estadísticas del sector turístico. Recuperado de: https://secturjal.jalisco.gob.mx/invierte-en-jalisco/ estadisticas

Sistema virtual dependiente del Instituto Nacional de Transparencia, Acceso a la Información y Protección de Datos Personales (20I5). Oficio núm.V-500-CAS/0 I84/20I5 [en poder de la autora].

Ugalde, V. (2007). "Sobre el gobierno en las zonas metropolitanas de México". Estudios demográficos y urbanos, 22(2), 443-460.

Verduzco, B. (20I3). Una utopía urbana (im)posible. La negociación infinita de planes de desarrollo urbano y prosperidad. Zapopan: Universidad de Guadalajara.

Ward,P.(20I I).“Repensando el espacio geopolítico metropolitano en México. ¿Cómo lograr un verdadero gobierno 
Bibliografía

Zentella, J. C. (2005). "Relaciones intermunicipales y gobernabilidad urbana en las zonas metropolitanas de México: el caso de la zona metropolitana de Xalapa". Estudios demográficos y urbanos, 20(2), 229-267.

y una gobernabilidad para todos?", en G. Capron, C. Icazuriaga, S. Levi, E. Ribera., y V.Thiébaut (eds.), La geografia contemporánea y Elisée Reclus (pp. 2 I I-244). México: COLMICH, CIESAS. 